Acta Poetica 27 (1)

PRIMAVERA

2006

\title{
Territorios afines: sociocrítica y feminismo
}

\author{
Silvia N. Barei \\ Adriana Boria
}

Desde una experiencia de trabajo compartida con Pierrette Malcuzynski, las autoras se proponen revisar críticamente las categorías propuestas por la teórica polaca para desarrollar una sociocrítica feminista. La heterogeneidad del texto, qué dice, cómo lo dice, sus no dichos, fueron propuestos por Malcuzynski como las modalidades sociocríticas de base, necesarias para situar la frontera donde se articulan socialidades y subjetividades.

Tomando como ejemplos algunos relatos de corte autobiográfico de Sylvia Molloy (argentina, teórica de literatura y narradora), las autoras reflexionan sobre las articulaciones texto/discurso/sociedad desde las nociones centrales de monitoring y subjetividad.

Taking as a point of departure their experience of work shared with Pierrette Malcuzynski, the authors intend to critically review the categories proposed by the Polish theorist in order to develop a feminist sociocritique. The heterogeneity of the text, what it says, how it says it, what it doesn't say, were considered by Malcuzynski as the basic sociocritical modalities, necessary to locate the border where socialities and subjectivities articulate themselves.

Analyzing examples from autobiographical stories by Sylvia Molloy (Argentine, literature theorist and narrator), the authors reflect upon the articulations text/discourse/society from the central notions of monitoring and subjectivity. 

Silvia N. Barei

Adriana Boria

Universidad Nacional de Córdoba (Argentina)

\section{Territorios afines: sociocrítica y feminismo}

La ficción siempre mejora lo presente.

S. Molloy

\section{Resplandor}

Hay una primera fecha de encuentro: 1993, julio, en Cocoyoc (México). VI Congreso Bajtín, Ramón Alvarado y Lauro Zavala mediante.

Hay una segunda fecha, muy distanciada de la primera: 2001, octubre, en Salta (Argentina). II Encuentro de Sociocrítica, Zulma Palermo mediante.

Hay, en ese mismo año, un curso en Córdoba y un re-conocimiento entrañable.

Hay, en el 2002, otro curso en Córdoba y el inicio de un trabajo conjunto que promete ser maravilloso.

Hay, en el 2003, una mala noticia y un curso, unas conferencias y una publicación frustrados.

Hay, en el 2004, una última llamada diciendo “¡Feliz Año, nos vemos...!" Y, luego, un silencio infinito.

Hay en el 2004, un encuentro en México con Tatiana Bubnova, con Martha Munguía, con Christina Karageorgou. 
Hay un dolor compartido y una propuesta: escribamos en su homenaje. Aunque no alcance, aunque no la traiga de regreso, aunque Pierrette sea ahora una mancha pálida en el campo visual. Y un gran resplandor que cruzó nuestras vidas con una intensidad desconcertante.

Y hay un poema donde la que se queda explica sus pesares porque se le ha vuelto "quebrado el corazón adentro".

$\mathrm{Y}$ hay ahora esta escritura prometida y este homenaje.

\section{Breve introducción}

Pierrette Malcuzynski ha sido una de las grandes estudiosas del pensamiento de Bajtín, a partir de cuya teoría desarrolló una serie de reflexiones y de conceptos operativos que le permitieron situar el texto literario como objeto de estudio. Y más concretamente, los textos escritos por mujeres, lo cual la llevó a repensar en clave de sociocrítica categorías teóricas para interrogarse acerca de la literatura femenina y a detenerse fundamentalmente en los aspectos de la producción y en el sujeto productor.

En este trabajo nos proponemos recuperar, aunque sea fragmentariamente, la experiencia del seminario que dictamos conjuntamente con Pierrette Malcuzynski en el año 2002, deteniéndonos en algunas de las preocupaciones que manifestó Malcuzynski para relacionar sociocrítica y feminismo. ${ }^{1}$

Creemos que esta preocupación formaba parte de un conjunto más amplio de reflexiones que constituyeron una zona de teorizaciones sobre las cuales y a partir de las cuales puede delimitarse el pensamiento de Malcuzynski. Así, reconocemos la filiación bajtiniana de su trabajo como un proceso de análisis teórico-crítico constante que implica simultáneamente un

\footnotetext{
${ }^{1}$ Malcuzynski, Barei y Boria, Seminario de postgrado dictado en la Facultad de Lenguas y el Centro de Estudios Avanzados de la Universidad Nacional de Córdoba, agosto de 2002, titulado: "Hacia una sociocrítica feminista".
} 
intento de profundizar y, quizás, complejizar algunas ideas del teórico ruso. De esta forma, creemos que la intención de Malcuzynski puede sintetizarse en una operación de triangulación entre el pensamiento de Mijaíl Bajtín, la sociocrítica y feminismo. Para expresarlo más adecuadamente, nos parece que ella dialoga con estos extensos bloques conceptuales a partir de los cuales recrea y transforma, mediante metáforas polifónicas, los principales aportes de estas teorías. Por ello es que, en este trabajo, realizaremos una breve exposición de los conceptos que consideramos más importantes en relación con las categorías de interdiscursividad, identidad y sujeto.

\section{El texto y su crítica}

Un primer ámbito de trabajo de las teorías sociocríticas es el que trata de abordar a la producción textual, definiendo al texto como un espacio "movedizo" y heterogéneo, que permite pensar las representaciones y articulaciones de lo social en un marco intersemiótico.

Al respecto, Claude Duchet (traducido por Malcuzynski) señala:

Un territorio se define por las fronteras: las del texto son movedizas [...] una zona indecisa donde se juega su suerte, donde se definen las condiciones de comunicación, donde se entremezclan las dos series de códigos: el código social [...] y los códigos productores o reguladores del texto. Las eventuales variantes pertenecen también a la zona textual. Allí son legibles la coherencia, la huella de las presiones culturales (Malcuzynski 1991, 31).

El texto se materializa como lugar de cruces de todo un sistema de remisiones interdiscursivas e intertextuales a partir de la selección que hace el escritor de lo dicho, lo pensable, lo legible a nivel social. La heterogeneidad del texto, qué dice, 
cómo lo dice, sus no dichos o no decibles son pensados por Malcuzynski como modalidades sociocríticas centrales, necesarias para situar la frontera donde se articulan socialidades y subjetividades. El texto contiene el espesor de lo social, una densidad que no es psicológica, sino cultural.

La tarea sociocrítica se precisa como la articulación de lo que constituye el texto, pero situándonos resueltamente del lado de su espesor (textual) y no de su profundidad (psicológica/ psicoanalítica) (Malcuzynski 1997-1998, 191).

La experiencia de escritura define al autor, pero también deja leer el espacio cronotópico en el cual se produce y el diseño del sujeto para quién se escribe. Tres polos o tres umbrales intersectados que constituyen el gran espacio textual, o mejor aún, la textualidad, lugar estructurado donde se materializa el entrecruzamiento de aquellas dimensiones.

Con respecto al sujeto productor particularmente, Malcuzynski se pregunta: ¿quién escribe, para quién, a quién, desde qué espacio geopolítico-sociocultural, cómo escribe y por qué?

Desde esta perspectiva, la propuesta crítica no ha de ser "reactiva", sino interactiva, palabra deudora del pensamiento bajtiniano quien habla de "interacción" de sujetos y de conciencias, y de "interrelación" de discursos, enunciados y textos (Bajtín 1985, 281-282 y 287).

Sin embargo, Malcuzynski va más allá con Bajtín, preocupada por el modo en que estas interacciones instituyen el mundo: entre lo "dado" y lo "creado", ella recupera fundamentalmente la tercera categoría: "lo proyectado" haciendo hincapié en el problema cognitivo acerca de los modos en que los sujetos perciben y elaboran sus relaciones con el mundo.

Lo que ha sido traducido en los trabajos de Bajtín en términos de dado (dannoe en ruso) y de creado (sozdannoe) remite muy concretamente a una serie de interacciones cognitivas 
detectables que no son binarias (ellas pueden ser conflictivas pero no en el sentido convencional de oposiciones) ni diseminadas en el flujo de la indeterminación. Igual que la relación dialógica, estas interacciones cognitivas se articulan en el seno de una red de relaciones fundamentalmente tripartitas que incluyen un supuesto (zadannoe). Yo prefiero hablar en términos de proyectado, en el sentido de "proyección" de horizontes (de diversas categorías) (Malcuzynski 1997-1998, 193).

La cultura se entiende entonces como una realidad vivida en interacciones de textos y subjetividades concretas y materiales, concebida según el funcionamiento articulado de un orden cognitivo articulado en la red compleja del espesor de sus textos.

\section{Orden retórico y orden cognitivo}

En un trabajo de investigación en curso, hemos tratado de mostrar los mecanismos a través de los cuales la cultura se manifiesta como este sistema de interacciones de textos y subjetividades, como señala Malcuzynski, y hemos hipotetizado que se rigen por un orden retórico que es fundamentalmente metafórico y que implica modos de cognición social (Barei, Pérez, Villa et al., 2005).

El sistema metafórico "modeliza" (Lotman 1996) la realidad en tanto que transmite modos de pensar y percibirla, es decir, existe una relación coherente entre los modos de enunciación y las prácticas de una sociedad y su sistema metafórico, ya que la construcción de los tropos no es "imparcial" y da cuenta de los axiomas que regulan una sociedad.

El principio de analogía (et.: "relación de semejanza") es la fuente básica de la metáfora y hasta tal punto impregna las prácticas de nuestra vida cotidiana que hasta las mínimas expresiones de ingenio, de manifestación de sentimientos o de 
enunciación de acciones concretas pueden adquirir un carácter metafórico.

Así, la coherencia del sistema cognitivo —-subjetivo e intersubjetivo- guarda correlación con cada metáfora que se produce: en nuestra sociedad, "bien" es "arriba-adelante" y "mal" es "abajo-atrás". De allí resultan por ejemplo las metáforas: "te vas para arriba", "sigue siempre adelante" o "estamos tocando fondo", "esto va para atrás".

Al pensar que el retorismo es una constante que permite trabajar a las culturas y que por ello se manifiesta en todos sus lenguajes, desde aquéllos de la vida diaria a los más complejos y plurivocales, coincidimos con la idea de Malcuzynski de que hay que observar la interacción de los textos que la rigen, teniendo en cuenta las circunstancias cronotópicas en las cuales éstos se producen.

Desde esta perspectiva, toda percepción del mundo es ideológica, así como lo es el contenido de la conciencia que no se construye en la individualidad, sino en el diálogo intersubjetivo. Por lo tanto, el uso metafórico del lenguaje permite pensar las relaciones entre lo social y lo simbólico, lo social y lo subjetivo.

De hecho, en el texto artístico y de manera dominante (como sistema modelizante de segundo grado según Lotman), la complejidad metafórica permite leer el mundo y el modo en que se conceptualizan realidades sociales y subjetividades complejas, desestabilizando principios ideológicos y estableciendo imágenes identitarias que muestran modos de comprensión del mundo individuales y sociales.

En términos lotmanianos, podríamos decir que lo que se nos plantea en la investigación es la "intersección de espacios de sentido" cuyos límites se van ensanchando y generando nuevas formas de la semiosis. En el límite más neto, podemos ubicar las intersecciones formadas por las metáforas lingüísticas cercanas al ámbito de la vida cotidiana y, las zonas en las 
que "en lugar de una línea neta hay una mancha", es decir, que corresponden a espacios no unívocos donde el grado más extremo lo constituyen las metáforas innovadoras de los textos artísticos (Lotman 1996, 35).

Si nuestro sistema perceptual y conceptual es metafórico y en la vida cotidiana alude a campos de comprensión inmediata que ocultan formas ideologizadas de la comunicación social, una metáfora —aún muy convencional— puede ser la única vía que tenga un sujeto para destacar aspectos de su experiencia o de sus sentimientos. Dado el carácter discursivo de la ideología — como bien lo señaló Voloshinov (1993) — esa metáfora puede ser utilizada seguramente con dos acentuaciones ideológicas diferentes, por sujetos pertenecientes a estratos socioculturales diversos.

Lo que importa no es tanto el problema de la verdad o falsedad de una metáfora - cuestión que interesa a los filósofos y que ya vimos que Nietzsche (1990) se encargó de discutir-, sino las percepciones e inferencias que se siguen de ella y el modo en que se refieren al mundo y a los sujetos. El mismo principio puede designar percepciones opuestas y, por lo tanto, construcciones diferentes del sentido, aún en sujetos pertenecientes a la misma cultura. También al mismo estrato social, si desempeñan roles diferentes o pertenecen a sexos o generaciones distintas.

Sostenemos entonces que, en el plano individual o personal, el orden metafórico es un orden cognitivo, esto es, rige modos de funcionamiento de la mente que nos permiten entender el mundo de determinadas maneras; mientras que en el plano social, es decir, colectivo, es un orden ideológico, que está ligado a formas de funcionamiento del poder que nos hacen (o quieren hacer) ver el mundo de determinadas maneras. Hay una refracción evidente de un orden sobre el otro, ya que desde la noción de intersubjetividad (Bajtín 1997, 2000) entendemos que los sujetos interactúan y construyen "realida- 
des" socialmente aceptadas según las condiciones que el medio impone a su existencia.

En términos de Malcuzynski, podríamos preguntarnos de qué manera el espesor de los textos proviene de la temporalidad histórica y de los componentes intersubjetivos de la creación. La temporalidad le concede memoria, la subjetividad le agrega una dimensión suplementaria que es la de la emergencia de nuevas formas de enunciación. Pero si bien el texto, cuanto más complejo sea, acumula mayor cantidad de información y, por lo tanto, mayores porciones de memoria y más posibilidades creativas, no debemos desconocer que hay una especie de sustrato o suelo común sobre el que trabaja todo texto cultural y que son los discursos sociales.

Las metáforas circulan así en discursos sociales hegemónicos o contradiscursos (Angenot, 2001) de un tiempo histórico, un estado de cosas, un sistema de prácticas y un código de comunicación (personal y social) de diversas esferas de la cultura. La plurivalencia de la metáfora ideologizada, la lucha por la respuesta y la transformación de los sentidos deviene un aspecto fundamental para entender de qué modo opera el orden metafórico como lugar de registro de las articulaciones entre lo social y lo textual.

De allí que, por ejemplo, los grandes ejes metafóricos de una cultura abren paso a nuevas luchas ideológicas que pueden leerse en sus producciones simbólicas. Éstas refuerzan estos ejes (el amor pasión da lugar a la novela de amor o la poesía trovadoresca) o los subvierten (las formas contemporáneas de la novela, las construcciones paródicas o satíricas, el humor de las vanguardias, etc.).

\section{Escuchar/escribir}

La idea de interacción de todos los planos de una cultura se relaciona con la de umbral ofrontera (nociones caras a los se- 
mióticos rusos), y que es reelaborada por Malcuzynski bajo la categoría de monitoring.

La traducción de este término al español presenta muchas dificultades, ya que la palabra monitoreo en nuestra lengua está más cerca de la idea de "control" o "revisión general" que de la idea de una interacción generalizada entre texto-discurso-sociedad, zonas diferentes donde se constituye también de modo diferente la subjetividad.

Tal como señala Malcuzynski, la noción de monitoring constituye un dispositivo metodológico

que busca discernir las capacidades inventivas y críticas del sujeto en el seno de la problemática de la mediación a nivel de la textualización. El punto de partida es la prolongación y la teorización de la noción bajtiniana de 'umbral' con el objetivo de poner de manifiesto los diversos niveles de la crisis que el sujeto atraviesa para articular y proyectar su discurso (Malcuzynski 1997-1998, 192).

En esta interacción generalizada, el monitoring es la capacidad atenta de "escucha" que ejerce el sujeto productor desde lo "dado" en un "estado de sociedad" (Angenot), hacia lo "proyectado" y la posibilidad de creación de textos en cuya materialidad significante se actualizan lo interdicursivo y lo intersubjetivo.

Cuando Malcuzynski formula a partir de estos conceptos las bases de una "sociocrítica feminista", lo hace teniendo en cuenta el lugar social de la mujer según la época que se considere y ubicando su discurso en esa tensión entre el querer y el poder decir/escribir.

La escucha, el monitoring, constituye la base de lo proyectado y su materialización en lo creado, el trabajo de la escritura como un tránsito de la discursividad social al texto, zona de frontera o intersticio en la cual el sujeto se "pone en crisis". 
Desdoblado, escindido de su situación personal, el sujeto pasa a ser "otro", puede nombrarse a sí mismo desde otro lugar (escriturario) y nombrar al otro en plano de igualdad.

Pensando en perspectiva feminista, Malcuzynski dirá: "no ya la mujer como el otro, sino la mujer $y$ el otro". 2

Retoma acá indudablemente la voz de Bajtín y sus reflexiones acerca del "autor responsable" que habla de sí mismo y de los otros (Bajtín 1997 y 2000).

$\mathrm{El}$ autor/la autora es un/a escucha que puede procesar y resemantizar en su propia enunciación el eco de las voces sociales; es alguien que puede dar cuenta de las condiciones de su tiempo y que tiene puesto el oído en la época, sobre todo en las zonas en que el territorio discursivo acusa la conflictividad de lo social.

En la puesta en texto de la escucha está presente la palabra del otro, así como sus silencios, la frontera polifónica (en términos bajtinianos, pero también musicales, como articulaba Malcuzynski) del decir y lo dicho, del sonido y el suspenso, de lo expresado entre líneas o entre susurros, de lo silenciado o censurado.

De este modo, el monitoring permite reflexionar acerca de la puesta en texto de todas las formas de la discursividad social, las retóricas intertextuales e interdiscursivas, las migraciones de sentidos y pensar en el del texto mismo como espacio de constitución de subjetividades marcadas por lo epocal.

\section{Territorios discursivos: caso 1. "Varia imaginación"}

Para poner en funcionamiento analítico el "concepto operativo" de monitoring, tomaremos como ejemplo un relato de la escritora argentina Sylvia Molloy, perteneciente a su libro $\mathrm{Va}$ ria imaginación (2003).

2 Reflexión que Malcuzynski toma de Myriam Díaz-Diocaretz, según lo aclaró en el citado curso de postgrado dictado en el 2002 en Córdoba. 
Para ser fieles al concepto hay que detenerse en primera instancia en el sujeto productor, dato importante en este caso porque hay dos aspectos de la vida personal y del quehacer de la escritora argentina que quedan inscritos en los textos: su residencia fuera del país y sus reflexiones como teórica de la literatura.

Sylvia Molloy es profesora, ensayista y escritora y dejó la Argentina -nació en Buenos Aires- a los veinte años. Estudió en Francia y en los Estados Unidos donde reside y da clases actualmente (Universidad de Nueva York). Entre sus ensayos merecen destacarse Letras de Borges (1979), Acto de presencia. La literatura autobiográfica en América Latina (1991-1996) y Hispanism and homosexualities (1998). Ha publicado dos novelas: En breve cárcel (1981) y El común olvido (2002). El texto Varia imaginación (2003) está compuesto por un conjunto de relatos breves agrupados en cuatro partes: "Familia", "Viaje", "Citas" y "Disrupción".

$\mathrm{Al}$ detenernos en el relato breve que da título también a todo el volumen, "Varia imaginación"3 (2003, 61-63), saltan a la vista en primera instancia las circunstancias personales que señalamos:

1. En una perspectiva autobiográfica y casi testimonial, el mundo personal vuelve como imagen de un pasado dejado atrás: el sujeto de la enunciación es alguien que va y viene de su tierra natal a otros lugares del mundo, lo cual equivale a decir que va y viene de los recuerdos al presente de la escritura, de las palabras de otros a las propias:

"A los dos o tres años en otra visita a Buenos Aires...", "Veinte años antes cuando el Charles Tellier estaba por partir rumbo a Le Havre llevándome a estudiar a Francia..."

2. La misma perspectiva autobiográfica ha sido reflexión particular de un hacer teórico que dio como lugar el estudio

${ }^{3}$ En adelante, las referencias de este libro se citarán en el texto señalando sólo la página. 
sobre la escritura autobiográfica en América Latina, Acto de presencia, publicado en inglés en 1991 y en español en 1996. En este texto Molloy señala que

[c]omo Na Cleme la vieja mendiga de Recuerdos de provincia de Sarmiento, quien gozando de su fama de bruja "trabajaba en sus conversaciones" para cimentar la prestigiosa imagen con que comenzaba a identificarse, el autobiógrafo "trabaja en su memoria" con la misma finalidad. Aun cuando menos definida que la de $\tilde{\mathrm{Na}}$ Cleme, la imagen de sí existe como impulso que gobierna el proyecto autobiográfico. Antes de fabricación individual, esa imagen es artefacto social, tan revelador de una psique como de una cultura $(1996,19)$.

Estas palabras describen acertadamente la escritura autobiográfica de Sarmiento y al mismo tiempo también los propios relatos de Molloy, en los que la ficción se erige en frontera desde donde construir memorias y recuperar genealogías y donde las voces y las miradas disímiles y hasta polémicas de los personajes arman un mundo que la escritora sabe siempre precario: "Le digo (que) la casa está apenas ampliada, sigue igual. Porfía que no, que ya no es la misma casa... Me doy cuenta de que es inútil insistir en lo contrario. Acaso los dos tengamos razón" (12).

Hay en el texto un tiempo personal (el recuerdo familiar) y un tiempo social (una época de la cultura argentina), un espacio personal (espacio de lo íntimo, la casa, las calles del barrio) y un espacio social (Buenos Aires, Francia) cuya "escucha" pasa por el tamiz de la memoria. Y la memoria está aliada a la imaginación, a la precariedad de toda reconstrucción posible de lo real. El narrador autobiográfico y el personaje relatan un mundo con el auxilio de la imaginación y suplen el escamoteo de "lo dado", de lo que efectivamente habrá sucedido, con "imaginaciones varias", tal como lo señala el título y también el comienzo del relato que nos ocupa: "Muerto 
mi padre, mi madre se replegó más y más en un mundo suyo, hecho de recuerdos y sobre todo, de conjeturas, invariablemente catastróficas" (61).

El eje de todo el relato se basa en la tensión que establece el juego de la ficción, entre el ser y el parecer, el decir y el saber, el recuerdo y la construcción de ese recuerdo.

Imaginación, invención, artificio aparecen como las pistas que desde el estatuto de la dicción construyen la ficción:

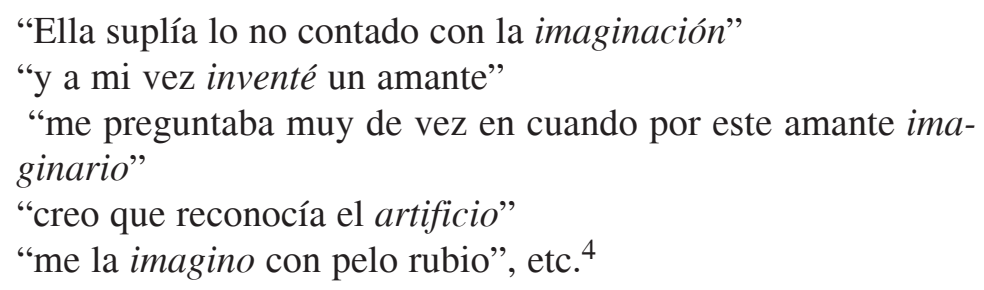

Este "monitoreo" de la palabra del otro, que es en realidad un "escamoteo", casi una mezquindad de la información que el sujeto narrador da al personaje (y al lector), tiene que ver con actuaciones enunciativas que se niegan a nombrar lo que socialmente está censurado: una sexualidad "otra", "qué amistades raras tenés" (61).

Lo "raro" encubre en primera instancia una interdiscursividad donde el silencio da cuenta de los lugares sociales del no decir.

El texto trabaja con una gradación que va de la sospecha (lo raro) a la invención de un estado "normal" — que, sin embargo, sigue sonando raro ("¿Vos tenés un hijo en París?..." "Inventé un amante francés...") — y del ocultamiento ("dije todo esto para ocultar sospechas") a la máscara intertextual ("cómo se llama, Julián... era el nombre que usaba Vita Sackville West en sus correrías por París con Violette Trefusis") (62).

${ }^{4}$ Subrayado nuestro. 
Mediante el monitoring, el relato recrea lugares sociales del decir donde se muestra la construcción del prejuicio y la censura en una época en que la cultura argentina exhibe su pacatería y usa metáforas ridiculizantes u obscenas para nombrar todo aquello "raro" o de lo que "no se habla" (la sexualidad de manera dominante, pero también lo judío y ciertas prácticas "nuevas" en los sesenta). ${ }^{5}$

Por otra parte, el alcance del monitoring enunciativo modifica sus fronteras ya avanzada la escritura/lectura del texto cuando permite el ingreso de un discurso antes censurado, o al menos callado:

A los dos, o tres años, en otra visita a Buenos Aires, decidí acabar con el engaño y le dije que Julián era, en realidad, una mujer. Quiso saber el nombre, se lo dije. ¿Es judía? Preguntó: no me creyó cuando le dije que no. Quiso saber si alguna vez había estado casada, no sé bien por qué. Divorciada, le dije. Y entonces dijo, con tono de desaprobación, me la imagino con pelo rubio: teñido, agregó después de una pausa (62).

Esta voz social que se hace audible muestra como el prejuicio pone una barrera entre lo dicho y lo escuchado, de modo que el territorio discursivo vuelve a expulsar los nuevos sentidos que debería haber incorporado, de acuerdo con una praxis social que sigue siendo negada por los sujetos:

Veinte años antes cuando el Charles Tellier estaba por partir rumbo a Le Havre llevándome a estudiar a Francia, al sonar la campana que llamaba a las visitas a bajar a tierra, me llevó a un lado y me dijo: en Europa hay mujeres mayores que buscan secretarias jóvenes pero en realidad lo que buscan es otra cosa. Sin más aclaración me besó y se fue, dejándome des-

${ }^{5}$ Para un estudio de los modos sociales de construcción de la homosexualidad y la homofobia, puede consultarse el libro de Gabriel Giorgi, 2004. 
concertada. Le recordé el incidente mientras almorzábamos. De veras, dijo sorprendida, no me acuerdo para nada (63).

La palabra concentrada, muy escueta. La descripción escatimada sintetiza la polifonía social (lo que no dice y antes estaba oculto, lo que no se quiere escuchar y se niega) y, sobre todo, esquematiza interdicciones mostrando un clima de época en el que el estado del discurso social (Angenot) permite reconocer las tensiones culturales.

El monitoring diseña las fronteras de un género conflictivo - el autobiográfico con sus múltiples matices-, en las fronteras de otro género - el sexual.

Señala al respecto Sidonie Smith:

Precisamente debido a que la autorrepresentación es discursivamente compleja y ambigua, en la escena de la escritura el artificio de la literatura lleva a cabo un embargo radical de la vida real. El yo, aparentemente familiar, se convierte en otro, en un extraño y la dirección que toma el embargo, es decir, la forma que toman las estrategias narrativas y dramáticas de la autobiógrafa, revela más sobre el momento presente de su autoexperiencia que sobre su pasado, aunque, desde luego, también nos informa de éste. Básicamente revela el modo en que la autobiógrafa se sitúa a sí misma y a su historia en relación a las ideologías culturales y a los modelos de identidad $(1991,97)$.

\section{Identidad y dialogismo}

Para continuar con nuestra recuperación del pensamiento de Malcuzynski hemos de abordar ahora, una serie de conceptos clave que le permitieron formular una sociocrítica feminista. Uno de ellos es el de "identidad".

En una conceptualización muy general, se podría decir que entendemos la noción de identidad como aquella percepción de nosotros mismos como individuos y como seres sociales. 
Malcuzynski vuelve a Bajtín y aunque este teórico no se refiere a la problemática de la "identidad", tal como la conocemos en la literatura actual, en sus obras se halla presente como reflexión conceptual, básicamente como una interrogación filosófico-antropológica acerca del hombre y sus condicionantes existenciales.

Como ya lo expresamos en otro trabajo (cf. Boria 2001), el término se populariza en las Ciencias Humanas luego de la Segunda Guerra, posiblemente a partir de la complejización de las condiciones sociopolíticas en el mundo. Hasta ese momento la palabra correspondía a un interrogante filosófico. Posteriormente se traslada a la antropología —en especial, aparece en la antropología estructural- para designar asuntos políticos, étnicos, económicos o culturales. En la actualidad el interrogante sobre la identidad se ha extendido al conjunto de la Teoría Social, quizás porque éstas son épocas de cuestionamientos profundos en cuanto a lo que se considera la "naturaleza" del hombre y concomitantemente al sentido de la vida. En contraposición a rasgos biologistas o trascendentalistas de la identidad, se podría decir que hoy se le concibe como un proceso en constante cambio.

El equivalente reflexivo en Bajtín de "identidad" es una extensa interrogación sobre el sujeto bajo la denominación específica de "persona". Con este término Bajtín hace referencia al individuo social. Mientras que el individuo se acerca a lo puramente biológico la persona para Bajtín es el sujeto social. En él se encuentra el conjunto de evaluaciones sociales del momento, de manera que se corresponde con la estructura ideológica de una sociedad. Las formas de percepción y de autopercepción, que se exteriorizan en el uso del lenguaje (signos) están impregnadas de las evaluaciones sociales del momento. De allí que las imágenes de las personas estén mediadas por estos signos cuya naturaleza es social. 
Desde aquí podemos recuperar una idea central en Bajtín acerca de la identidad: más que una definición ontológica ésta tiene que ver con una entidad relacional. Con ello, Bajtín intenta descubrir y proponer cómo se construye socialmente un sujeto. Distinguimos dos momentos como consecuencia de su postura, uno descriptivo: cómo es, qué se oculta, y un segundo momento, ético: cómo debería ser.

Su posición es parte de un debate que proviene del siglo XVIII y que supone la negativa hacia posturas idealistas: el correlato de este punto de vista es su crítica al idealismo lingüístico cuyo representante máximo (Bajtín califica a esta corriente de "magistral") es Alexander von Humboldt. No existe la posibilidad de un sujeto monádico ni autónomo como se plantea desde la tradición clásica de la modernidad. En esta orientación, no habría pautas identitarias monológicas, que se acercan a una homogeneidad tranquila y sin conflictos; por el contrario, las identidades se construyen en dialogía y su signo es la diferencia y la heterogeneidad. De allí que puedan reconocerse cualidades heterogéneas y diferenciales en las identidades sociales y, particularmente, en aquellas que llamamos genéricas.

\section{La teoría feminista como crítica a la noción de sujeto}

No es éste el lugar para historizar los aportes y los recorridos de las teorías feministas; sin embargo, resulta imprescindible realizar una breve introducción donde se planteen algunos problemas que nos permitan encuadrar estas reflexiones.

Si bien la modernidad — nos referimos a los aportes de la teoría social a partir del siglo XIX- propone un sujeto cuyas facultades naturales son la igualdad, la fraternidad y la libertad, dichas cualidades desnudan las contradicciones de la retórica libertaria. Se advierte así que esta noción de sujeto y sus atributos se refieren al varón. La igualdad es la igualdad de los varones. Simultáneamente, como una estrategia de justifica- 
ción de esa falsa igualdad, se crea la "diferencia", pero en este caso entendida como falla o carencia. Se establece entonces una tabla de jerarquías que distribuyen cualidades marcadas como positivas o negativas según los sexos. El espacio social por excelencia para la mujer es el espacio doméstico, mientras que su participación en el espacio publico es visto peyorativamente (cf. Comte, Balzac, etc.). ${ }^{6}$

Desde el siglo XIX en adelante, las mujeres se movilizaron y obtuvieron diversas reivindicaciones y derechos, como también cambios en las prácticas cotidianas y públicas. Sin embargo, a pesar de estas múltiples luchas y reclamos, estas cualidades de la "condición femenina" se mantienen con sus variantes y transformaciones en el imaginario contemporáneo. Se comprende entonces la importancia que posee para la teoría el debate acerca de la sujeto mujer: su diferenciación, su constitución, su diversidad, a los fines de conferirle tanto su estatuto teórico como valor hermenéutico.

En esta zona de problemas, un texto fundante en la teoría feminista es El segundo sexo de S. de Beauvoir. Ella realiza una primera operación teórica que consiste en desmontar, en clave filosófica, el concepto de sujeto de la modernidad. Precisamente, es Beauvoir quien primero diferencia sexo y género, cuando avanza con su conocida afirmación: "No se nace mujer, se llega a serlo".7 Con ello, reconoce la naturaleza cultural de ciertas pautas de comportamiento "femenino" al tiempo que desnaturaliza ciertas convenciones aceptadas socialmente. Mas allá de las críticas que puedan hacerse a su

${ }^{6} \mathrm{Si}$ bien nos situamos en el siglo XIX como un momento central en la constitución del feminismo, no desconocemos la presencia de voces que con mucha antelación denunciaban situaciones de injusticia y opresión para las mujeres. Mencionamos, sólo por caso, una de las más conocidas, como es Mary Wollstonecraft, 1791.

${ }^{7}$ No desconocemos las críticas realizadas a esta categoría por su formulación desde un lugar de enunciación eurocéntrico (mujeres, occidentales, blancas, heterosexuales, de clase media, etc.) y su desconocimiento de la formulación previa de esta condición por otras mujeres (por ejemplo, no europeas, negras, esclavas). Al respecto puede consultarse Claudia Lima (2002). 
postura, este acuerdo es unánime entre quienes se dedican a pensar sobre la "condición mujer". 8 Tampoco es discutible el impacto de Beauvoir en teóricas de la talla de Kate Millet o J. Butler, entre otras. Lo cierto es que encontramos constantes en el discurso feminista que actualmente son objeto de debate: junto con la noción de sujeto existe hoy una disputa sobre las definiciones y relaciones sexo/género.

En el caso de la noción de sujeto, se trata de deconstruir - en el sentido de desnaturalizar - ciertos presupuestos relacionados con la condición femenina y que están contenidos en la misma noción. Como interrogante filosófico, su definición contiene al mismo tiempo un posicionamiento que marca una divisoria de las aguas. ${ }^{9}$

En esta encrucijada teórica se sitúa la reflexión de Pierrette Malcuzynski. Creemos no desvirtuar su pensamiento si consideramos al sujeto como una construcción cultural en donde se juega un campo de tensiones, que oscilan entre lo individual y lo colectivo, lo económico y lo político. Este presupuesto filosófico orienta la reflexión, al mismo tiempo que reconocemos la importancia teórica y el cambio de paradigma que significó el "giro lingüístico" en las ciencias del hombre. Junto con Malcuzynski, sostenemos que el punto de vista de Bajtín sobre la subjetividad nos parece precursor de trabajos posteriores sobre el tema, como también impulsor de aperturas críticas en el campo de los estudios de género.

${ }^{8}$ Como texto fundante señalamos su recepción en otras teóricas del campo tales como Silvie Chaperon, Luce Irigaray o Judith Butler.

${ }^{9}$ Las diferentes concepciones de sujeto están delimitadas y estudiadas en el trabajo de Liz Bondi que se cita en la bibliografía final. Por otro lado, queremos agregar que el trabajo crítico de la teoría feminista implica, tal como lo mencionamos anteriormente, el desmontaje de la noción de sujeto cuyas legibilidades y legalidades excluyen a lo diferente o lo subordinan en relación con un modelo universal incuestionable. De esta forma, podemos asimilar esta perspectiva al pensamiento bajtiniano cuando concibe a la actividad intelectual como una práctica que opera con base en la "desconfianza" (Bajtín 1986, 294). La "desconfianza" supone un intenso trabajo de desmontaje de aquellas categorías, por lo cual podemos situar a Bajtín en las corrientes que se denominan filosofías de la sospecha. 
Si bien el pensamiento bajtiniano - profundamente pluralista - no ha tratado el problema de la mujer, caeríamos en un error si no lo ubicamos en un contexto histórico preciso. Paradójicamente, creemos que esta "omisión" se presenta como una herramienta adecuada que quizás nos permita, más que resolver dudas, abrir líneas de interrogantes que consideramos positivos. Esta productividad de Bajtín ha sido reconocida por destacadas teóricas feministas - Fraser, Colaizzi, Díaz-Diocaretz, entre otras-, quienes incorporan sus presupuestos teóricos. Malcuzynski se integra también a este grupo, tratando de repensar categorías nucleares del texto bajtiniano, que resultan productivas en relación al sujeto mujer.

En este sentido, Malcuzynski sostiene que el pensamiento bajtiniano actualiza diversos problemas teóricos del debate contemporáneo, en especial aquellos interrogantes de interés relacionados con los estudios de mujeres, puesto que su perspectiva transdisciplinaria provee un instrumental adecuado.

\section{La critica feminista dialógica}

Desde el campo complejo y problemático que diseñan estos conceptos, Pierrette Malcuzynski trata de constituir, y aquí debemos subrayar su rol premonitorio, una sociocrítica feminista. Ello implica el detenimiento en textos y productos de la cultura cuando "el sujeto que habla y que escribe es una mujer" $(1996,25)$.

Inmediatamente, el interrogante que surge supone un nivel de complejidad que se suma a las disputas teóricas que hemos mencionado anteriormente: ¿qué debemos tener en cuenta, cuando la perspectiva de acercamiento a los textos escritos por mujeres es la sociocrítica? La respuesta de Malcuzynski se sintetiza en una idea central que se basa en el dialogismo bajtiniano: no se trata aquí de un ser "con" ni un ser "para", sino de un sujeto "y" otro, como ya hemos señalado. 
La categoría bajtiniana que subsume esta dinámica compleja es la de intersubjetividad, ese especial posicionamiento del hombre que condiciona su ser en el mundo. En palabras de Bajtín:

Yo me conozco inicialmente a través de los otros: de ellos recibo palabras, formas, tonalidad para formar una noción inicial de mí mismo. [...] Como el cuerpo se forma inicialmente dentro del seno materno (cuerpo), así la conciencia del hombre despierta envuelta en la conciencia ajena. Ya más tarde comienza la aplicación a sí mismo de palabras y de categorías neutras, es decir, la definición de uno mismo como persona sin relación con el yo y con el otro $(1982,360)$.

Esta perspectiva sobre las relaciones dialógicas nos provee de buenos argumentos acerca de las políticas de construcción del sujeto mujer.

La intersubjetividad como dinámica social conforma sujetos/"personas" como un conglomerado heteróclito en el que se inscriben lenguajes distintos. El sujeto mujer no está al margen de estas interacciones que oscilan entre los acuerdos y las polémicas. Podemos leer estas disputas en los más variados géneros discursivos como lugares de objetivación de las prácticas de una sociedad: en los enunciados más moleculares (el insulto, la controversia, el debate, la declaración amorosa) y en los grandes relatos contemporáneos (los textos literarios, los filmes, los medios de comunicación).

Sin embargo, más allá de este conjunto de enunciados, que como hemos señalado implica diferentes mediaciones culturales, existe, en el edificio teórico de Malcuzynski, el reconocimiento de la categoría de género ${ }^{10}$ como una mediación intersubjetiva que construye normas y pautas de conducta, y que asimismo delimita ciertos modos de producción creativa.

${ }^{10}$ Ver la propuesta de Scott. 
(Curso de postgrado. Córdoba, 2002). La categoría de género es una variante más que se integra a esta idea de identidad como entidad relacional e histórica.

Un rasgo a destacar es que la idea de "el otro" en Bajtín no existe sino como marca de la diferencia y, al mismo tiempo, como marca de una incompletud. Esta idea de la diferencia, que se expresa en diversas axiologías, la hallamos en distintos momentos del desarrollo teórico:

La vida conoce dos mundos axiológicos por principio diferentes, pero relacionados entre sí: el yo y el otro, y en torno a estos dos centros se distribuyen y se componen todos los momentos concretos del ser (Bajtín 1997, 79).

Además, señalemos que "el otro" en Bajtín se ubica siempre relacionado con el plano ético, con la esfera del "deber ser": "Esta desintegración arquitectónica en yo y en todos los otros para mí, no es pasiva o fortuita sino que tiene un carácter del deber ser activo" (Bajtín 1997, 80).

Podríamos afirmar entonces que la identidad, como interrogante con un "mí mismo", nunca se construye con un solo individuo. La subjetividad, en tanto proceso de autopercepción, es una percepción dialógica. Aún las valoraciones más íntimas se mueven con un "otro", que es lo que nos permite hablar de una "socialidad" en las prácticas amorosas, por ejemplo. Por otro lado, la propuesta de Bajtín sobre la subjetividad y su interacción vuelve a problematizar la política de identidades; siguiendo su pensamiento, diremos que el acto ético responsable y activo debería guiar estas políticas, puesto que "la crisis contemporánea es básicamente la crisis del acto ético contemporáneo" (Bajtín 1997, 61).

En plena coincidencia con este postulado, leemos en Malcuzynski: 
Más que trabajar sobre los problemas eternos de la representación, quisiera proponer una reevaluación sociocrítica de la constitución del sujeto y del discurso sobre la construcción de la identidad sociocultural, una lectura que, fundamentada en la premisa bajtiniana de la heterogeneidad social de la circulación del lenguaje y de la comunicación, restituya al análisis una problemática cognoscitiva en el seno de una economía epistémica de responsabilidad (1996, 27).

Pero tal vez uno de los aspectos más ricos del dialogismo bajtiniano sea su reconocimiento del otro como diferencia radical. No como lo ha entendido el estructuralismo en términos dicotómicos, pero tampoco como lo sostienen algunas posturas posestructuralistas: la diferencia como borramiento de todos los límites, como una ambivalencia indecidible. Así, para Bajtín el reconocimiento de la diferencia es el inicio del propio autoconocimiento y de la autojustificación (Bajtín 1997, 147-156). Simultáneamente la diferencia es una diferencia cronotópica: la inclusión en un momento histórico preciso. Encontramos un concepto en Malcuzynski que funciona a modo de metáfora teórica pero que se relaciona con esta idea de crítica al pensamiento binario con base estructuralista o posestructuralista:

Yo me basé en lo que diferencial significa en matemáticas, y específicamente en mecánica, es decir un mecanismo que entrelaza tres móviles imponiendo las condiciones para que cada una de las velocidades simultáneas, sea proporcional a la suma o a la diferencia de las otras (1997-1998, 213).

La posibilidad de una diferencia comprendida de esta manera nos permite pensar lo que desde hace ya mucho tiempo nombramos como libertad, puesto que ella no se efectúa en un vacío sin nombre sino en una serialidad textualizada con recorridos rizomáticos e incompletos, pero con algunos sentidos más o menos estables. 
Como hemos dicho antes, en este marco uno de los itinerarios posibles sería el reconocimiento de todo aquello que no se dice, de lo presupuesto en los discursos, aquello que está borrado u oculto. De esta manera, nos sería permitido reconocer "lo dado" para proponer "lo creado". Es en esta zona de tensiones en donde el sujeto mujer puede encontrar diversas maneras de neutralizar, reapropiar o restaurar ${ }^{11}$ los materiales heterogéneos del mundo social. Retomamos aquí el interrogante del que partimos, ¿qué actuaciones posibilitan la construcción de identidades? A la luz de estas reflexiones tal vez se pueda afirmar que más allá de reconocer este proceso como complejo y mudable hay impactos que provienen de zonas simbólicoprácticas que afectan las identidades sociales e involucran a aquellas que denominamos identidades genéricas. Esta dinámica no es permanente: también está marcada históricamente. Debemos distinguir, por ejemplo, el impacto de la narrativa literaria del siglo XIX en la constitución del "carácter femenino" y el impacto decisivo de los medios en el siglo xx, pero también debemos tener en cuenta otros factores como el desarrollo institucional y normativo diverso.

Otro aspecto crucial en este proceso, es lo que Fraser (1997, 20-26) denomina "las injusticias distributivas", refiriéndose a las diferencias económicas. No nos parece excesivo, en este contexto de pobreza y desaliento globalizado, expresar la importancia de políticas económicas que entrecruzadas con prácticas culturales provocan estados de marginación y exclusión. Es ya aceptada por diversos sectores del feminismo la ambivalencia que conlleva el mismo término generalizante "mujer", cuyo presupuesto entimemático se refiere a un modelo legitimado social y culturalmente. Como es sabido, del cuestionamiento a esta denominación proviene uno de los avances

${ }^{11}$ Estas operaciones — apropiar, restaurar, neutralizar - han sido tomadas del artículo de Myriam Díaz-Diocaretz, "La palabra no olvida de dónde vino: para una poética dialógica de la diferencia”, 1993. 
teóricos más importantes en el desarrollo de una teoría del género. Se incorporan además a esta polémica las variantes económicas como constitutivas de las identidades genéricas.

Acordamos, en consonancia con Pierrette Malcuzynski, el desarrollo de una teoría crítica de la identidad que contenga diferencia y desigualdad, reconocimiento y distribución, en palabras de Fraser.

En este marco, hay una dimensión que proponemos como un factor que articula ambos términos. Nos referimos a la ética. Esta última noción, no lo olvidemos, es central en la dinámica social de Bajtín, junto con la idea de responsabilidad. Pareciera que ambas colaboran en este "deber ser" propuesto por el autor y repensado por Malcuzynski. Una idea de ética que incorpora materialidades históricas y nuevas formas de solidaridad: quizás este podría ser un programa que aglutine identidades diversas.

\section{Territorios discursivos. Caso 2. "Gestos"}

Visto este desarrollo teórico, nos preguntamos cuáles son, en las escritoras, los modos de actualizar ciertas constantes que manifiesten una estrategia, una decisión, o una búsqueda de graficar perfiles identitarios que iluminan y que, al mismo tiempo, quiebran los silencios o los territorios negados.

Si elegimos a Silvia Molloy fue porque en ella nos parece encontrar, más allá de un deleite estético, una ética del detalle, es decir, un especial modo metonímico de construcción de la escritura que nos impulsa a reflexionar sobre aquellas zonas de la cotidianidad que, aunque etéreas y sutiles, nos constituyen como sujetos: "Era un gesto trivial, anodino: tomar el borde del mantelito que se tiene adelante y plegar el borde dos o tres veces sobre sí mismo en dirección al plato, como quien pliega una hoja de papel..." (71). 
También creemos advertir en la representación de lo íntimo un ritmo peculiar, un tono, un "temblor de la memoria" que nos acerca una experiencia compartida.

\section{"Gestos"}

Hay en el libro un apartado titulado "Citas". El término citas nos reenvía a un encuentro programado, encuentro de cuerpos (encuentro el cuerpo del otro en un bar, una plaza, una esquina) o a un decir de otro, un encuentro verbal (encuentro la palabra de otro en el texto). Uno u otro significados se actualizan en las pequeñas historias de "Citas".

En este apartado un relato, "Gestos", nos llama la atención pues se trata allí de amalgamar el lenguaje corporal, como cuerpo significante ("se inscribió en la memoria de mi cuerpo" dice la narradora-hija), con el lenguaje verbal: "Es como si citara a mi madre" (72).

Así, se podría resumir el texto que nos ocupa como el relato del recuerdo de un gesto de la madre. El "suceso"- en el sentido de Barthes- es la repetición del mismo gesto por la hija. La hija, sorprendida, se da cuenta de la repetición. Se construyen de este modo los personajes centrales del relato, la hija y la madre: "Hace poco sentada a la mesa, me sorprendí repitiendo un gesto de mi madre" (71).

Como casi todos los relatos de Silvia Molloy, es un relato en primera persona. ${ }^{12} \mathrm{Si}$ retomamos la frase de Benveniste:

12 Se podría especular mucho acerca del uso y abuso de la primera persona, sobre todo en cierta literatura hoy escrita por mujeres, donde la presencia del yo se convierte no sólo en rasgo de un género discursivo (véase el caso del género autobiográfico), sino en un rasgo de estilo. Podríamos arriesgar y decir también que su uso es un rasgo de género en el sentido de gender. Otra reflexión para agregar es la importancia que tiene el contexto sociohistórico en el uso de este pronombre personal. Por ejemplo, la abundancia de autobiografías en el siglo XIX, que se correspondía según los especialistas con una búsqueda de la identidad en el sentido de una definición o redefinición de algunas cualidades o atributos para los sujetos. La utilización del yo narrativo se presenta en la actualidad tal 
"Es ego quien dice ego" (1979), puede comprenderse el estatuto identitario, la función crucial del deíctico, como conformador del yo. Pero tal aproximación no es suficiente. Si seguimos a Bajtín, sabemos que "la persona" se constituye en una relación dialógica cuya singularidad es la tercera voz, que para Malcuzynski es el diferencial. No sólo hace falta un yo y un tú que responda. Hace falta pensar que el "yo soy" es respuesta a ese otro "yo soy" como "Yo también soy". ${ }^{13}$ Esta dialogía se hace presente en el texto mediante la figura - forma textual que se destaca y al mismo tiempo se reitera - de la repetición.

El gesto de la madre que se adquiere, a pesar de ser repetido, no es idéntico al anterior, es decir, al gesto de la madre. La repetición sólo vale como descubrimiento de una filiación y de recuperación de una memoria.

Si la cita es la aparición en el enunciado de la voz del otro al mismo tiempo que el mantenimiento de la memoria, el gesto como cita cumple funciones similares:

Ahora este gesto mínimo, inconsciente, que se inscribió en la memoria de mi cuerpo cuando observaba a mi madre desamparada, me señala lo contrario. Es como si citara a mi madre, y la cita me inquieta porque no la puedo controlar (72).

Lo cierto es que la imagen a la que refiere como una constante es la de la madre. Pareciera que esta imagen se prefigura no sólo como el tú, sino también como el tercero, pues a él se refiere, y repite, el relato:

vez como una estrategia política o también como política identitaria por parte de las escritoras mujeres.

13 Remitimos a la siguiente afirmación de Bubnova: "El otro es la primera condición de emergencia del sujeto que se dice 'yo'. El postulado ontológico no sería entonces 'yo soy' o, pongamos por caso, 'pienso, luego soy' —ipor qué, dice Bajtín, sólo por haber advertido que pienso, debo considerar que pienso la verdad?-, sino un 'yo también soy', mediante el cual se otorga la primogenitura al otro" (Bubnova 2000, 17). 
"Mi madre y yo nos parecíamos físicamente..."

"me había esforzado por no parecerme a mi madre"

"es como si citara a mi madre"

"imponer distancia con respecto a mi madre"

¿Tal vez la construcción de una identidad se produce en este movimiento constante de repetición? ¿Podríamos entonces concluir que la repetición, como en los juegos o en ciertos objetos artísticos, es un principio identitario y diferencial?

Lo cierto es que en el texto se hace presente, también, la figura del descubrimiento. La hija encuentra en sí misma rasgos semejantes a los de su madre y se des-cubre: "La sorpresa fue tan fuerte que obliteró todo lo que me rodeaba, como una foto sobreexpuesta" (71).

Sin embargo, el descubrimiento - como principio de identidad - adquiere un sentido unitario en la medida en que se comprende como un proceso de permanente cambio. El relato es, en sí mismo, la demostración de ese proceso.

Aquello que no está dicho parece ser entonces la permanencia de un linaje, de una herencia que se concreta en "un pobre gesto insignificante". Tal vez porque la gestualidad está inscrita en el cuerpo y prevalece como una marca, un sello, un tatuaje.

\section{Breves conclusiones}

En esta somera aproximación a un campo teórico complejo, hemos propuesto una travesía o, más bien, derroteros diversos, por territorios afines: el de la sociocrítica y el feminismo, el de la teoría y la creación, el de la reflexión y la pasión.

En esta "zona indecisa", la experiencia individual y social define sujetos y textualidades en interacción, a partir de la cual se elabora un modo de pensar la teoría desde la escritura y un modo de escribir desde el suelo fértil de la teoría. 
Pensar la posibilidad de diseñar un campo problemático como el de una sociocrítica feminista actualiza cuestiones teóricas que atraviesan los debates contemporáneos: discursividades, subjetividades y modos de representación, donde lo femenino es legible desde un "orden" cognitivo e ideológico que es, ciertamente, un lugar diferencial.

Al ejemplificar con textos de la escritora argentina Silvia Molloy, hemos podido señalar modos de construcción de lo íntimo, lo privado y lo cotidiano como zonas sobre las cuales se sostienen las memorias personales y las de toda una comunidad con sus marcas históricas, aspectos centrales para la articulación entre texto artístico e historia.

\section{Bibliografía}

Angenot, Marc, Interdiscursividades, Córdoba, Argentina, CEA, Universidad Nacional de Córdoba, 2001.

Bastín, Mijaíl, Problemas literarios y estéticos, La Habana, Ed. Arte y Literatura, 1986.

—, Estética de la creación verbal, México, Siglo XXI, 1985.

_, El marxismo y la filosofía del lenguaje, Madrid, Alianza, 1992.

—, Hacia una filosofía del acto ético. De los borradores, Barcelona, Anthropos, 1997.

—, Yo también soy. (Fragmentos sobre el otro), México, Ed. Taurus, 2000.

BALZAC, Honorato de, "Fisiología del matrimonio", La comedia humana [1830-1850...], tomo XVI, México, Colección Málaga, 1958.

Barei, Silvia, Texto/discurso. Recorridos teóricos, Córdoba, Argentina, Epoké, 2001.

Barei, Silvia, Pérez, Villa, et al., Lenguaje y cultura. El orden metafórico en la vida cotidiana, el arte y los medios, Córdoba, Argentina, Facultad de Lenguas, Universidad Nacional de Córdoba, y Ferreira editor, 2005.

Beristáin, Helena, Diccionario de retórica y poética, México, Ed. Porrúa, 2003. 
Benveniste, Emile, Problemas de lingüística general, tomos I y II México, Siglo XXI, 1979.

Bond, Liz, "Ubicar las políticas de identidad", Debate Feminista, año 7, vol. 14, México, 1996.

Boria, A., "Identidad y subjetividad. Aproximaciones", Discurso social argentino 4, Córdoba, Argentina, Topografia, CEA-UnC, s/f.

Bubnova, Tatiana, "Palabra propia, palabra ajena", Tópicos del Seminario, núm. 5, México, Universidad de Puebla, 2001.

Comte, Augusto, "Correspondance générale et confessions", tomo III, Archivo positivista, Mouton-La Haye, Ecole des Hautes Etudes en Sciences Sociales, Paris, 1977.

Mouffe, Chantal, "Por una identidad nómade", Debate Feminista, año 7, vol. XIV, 1996.

Díaz-Diocaretz, Myriam, "La palabra no olvida de dónde vino: para una poética dialógica de la diferencia", Breve historia feminista de la literatura española, Madrid, Anthropos, 1993.

FrASER, Nancy, Iustitia interrupta. Reflexiones desde la posición postsocialista, Bogotá, Siglo del Hombre, Universidad de los Andes, 1997.

Giongi, Gabriel, Sueños de exterminio. Homosexualidad y representación de la literatura argentina contemporánea, Rosario, Argentina, Ed. Beatriz Viterbo, 2004.

Lakoff, G., Johnson, M., Metáforas de la vida cotidiana, Madrid, Cátedra, 1998.

Lima Costa, Claudia DE, "Repensando el género: tráfico de teorías en las Américas", en Perfiles del feminismo iberoamericano, María Luisa Femenías (comp.), Buenos Aires, Catálogos, 2002.

Lotman, Iuri, La estructura del texto artístico, Madrid, Itsmo, 1978.

—, "La memoria a la luz de la culturología", Criterios, comp. y trad. D. Navarro, núm. 31, enero-junio, La Habana, 1994.

—, La semisofera I, Valencia, Frónesis-Cátedra, Universitat de Valencia, 1996.

MalcuZYnski, Pierrette, Entre-dialogues avec Bakhtine ou la sociocritique de la (dé)raison polyphonique, Amsterdam, Rodopi, 1992. 
MalcuzYnski, Pierrette, "Quelques rélexions sur le discours musical chez Bakhtine", RS-SI. Revista de la asociación canadiense de semiótica, vol. 18, Montréal, 1998.

—, "Bajtín, literatura comparada y sociocrítica feminista", en Poligrafías, Revista de literatura comparada, México, Facultad de Filosofía y Letras, UnAm, 1996.

-, "A propósito de la sociocrítica", Acta Poetica, 18-19, México, UNAM, 1997-1998, pp. 189-218.

-, Sociocríticas. Prácticas textuales. Cultura de fronteras, Amsterdam, Rodopi, 1991.

Molloy, Sylvia, Acto de presencia, la literatura autobiográfica en América Latina, s.p.i., 1991-1995.

-, Varia imaginación, Rosario, Argentina, Ed. Beatriz Viterbo, 2003.

Monegal, Antonio, "La metáfora en teoría", Eutopías, vol. 69, Centro de Semiótica y Teoría del Espectáculo, Universitat de Valencia y Asociación Vasca Semiótica, 1994.

Mouffe, Chantal, "Por una identidad nómade", Debate Feminista, año 7, vol. 14, México, 1996.

Nietzsche, F., Sobre verdad y mentira en sentido extramoral, Madrid, Tecnos, 1990.

Requena, Julio, El principio metafórico, Córdoba, Alción, 1996.

Ricoeur, Paul, La metáfora viva, Madrid, Trotta, 2001.

SMith, Sidonie, "Hacia una poética de la autobiografía de mujeres", Anthropos, núm. 29, Barcelona, 1991.

Voloshinov, V., Marxismo y filosofía del lenguaje, Madrid, AlianZa, 1993.

Wollstonecaft, Mary, Vindicación de los derechos de las mujeres, Buenos Aires, Perfil, 1998 (1a. ed., 1791). 
